\title{
Um panorama das intervenções comportamentais para tratar estresse e ansiedade em atletas: revisão bibliográfica
}

\author{
MARIANA DE ARAÚJO ANDREOLI \\ Universidade Presbiteriana Mackenzie (UPM), São Paulo, SP, Brasil. \\ E-mail: mari_andreoli@hotmail.com \\ THAÍS CABRAL DE OLIVEIRA \\ Universidade Presbiteriana Mackenzie (UPM), São Paulo, SP, Brasil. \\ E-mail: thais.cabral94@gmail.com
}

\section{DANIEL SÁ RORIZ FONTELES}

Universidade Presbiteriana Mackenzie (UPM), São Paulo, SP, Brasil.

E-mail: danfonteles@gmail.com

\section{Resumo}

O esporte, na contemporaneidade, vem ganhando cada vez mais importância e visibilidade, sobretudo por valorizar o esforço físico e intelectual desprendido por atletas de alto rendimento em suas diversas categorias. Esses atletas frequentemente enfrentam estresse e ansiedade antes de desempenharem suas funções. Objetivou-se com o presente trabalho descrever os fatores que eliciam essas reações emocionais, identificar instrumentos utilizados para a avaliação e o diagnóstico delas em atletas, e apresentar intervenções psicológicas e/ou comportamentais utilizadas. Para tanto, procedeu-se a uma revisão bibliográfica dos artigos científicos publicados em periódicos nacionais, sendo incluídas pesquisas empíricas e de revisão, publicadas entre 2010 e 2017, sobre situações de estresse e ansiedade em atletas. O referencial teórico utilizado para a discussão do tema foi a análise do comportamento e o behaviorismo radical. Como resultado, analisaram-se todos os antecedentes, os instrumentos de avaliação e as intervenções realizadas. Ao final são descritas algumas intervenções apresentadas como eficazes na literatura, porém ainda sem dados empíricos coletados no Brasil. Conclui-se que, quando o esporte competitivo é aliado ao bem-estar do atleta, este apresentará melhor desempenho. A atuação do psicólogo, 
nesse contexto, tem como objetivo principal o desenvolvimento de autoconsciência, autoconfiança e inteligência emocional.

\section{Palavras-chave}

Psicologia do esporte. Comportamento. Estresse. Ansiedade. Desempenho.

\section{INTRODUÇÃO}

O esporte, na modernidade, vem ganhando cada vez mais importância e visibilidade, sobretudo por valorizar o esforço físico e intelectual desprendido por atletas de alto rendimento em suas diversas categorias. Esses atletas frequentemente enfrentam estresse e ansiedade antes de desempenharem suas funções. Esse fenômeno psicossocial pode ser analisado do ponto de vista de contingências comportamentais e metacontingências, envolvendo a verificação de antecedentes e consequências do comportamento a fim de compreender suas relações funcionais com o ambiente. Esse conhecimento deriva da análise do comportamento (analysis of behavior) iniciada por Skinner (1965).

Existem poucos psicólogos especializados e atuantes, além de escassas publicações científicas nacionais na área do esporte. Entretanto, os eventos esportivos, como a Copa do Mundo e os Jogos Olímpicos, mostram-nos a importância de trabalhar questões como ansiedade, estresse, foco/concentração, atenção, tomada de decisão, coesão de grupo, entre outros aspectos inerentes à prática esportiva de caráter competitivo. Após o notável resultado de 7 a 1 contra a Alemanha na semifinal da Copa do Mundo de 2014, questões do âmbito emocional, psíquico e cognitivo dos atletas começaram a ser consideradas, uma vez que a diferença na preparação psicológica e emocional das duas equipes ficou explícita em campo e foi tema de diversas publicações de jornalistas e psicólogos (BRITES, 2015).

Dessa forma, considera-se de grande relevância para a academia e para a psicologia do esporte o desenvolvimento deste trabalho, que consiste em uma revisão bibliográfica sobre o tema de estresse e ansiedade em atletas, além de uma discussão e apresentação de intervenções psicológicas possíveis para essa problemática, tendo como referencial teórico base a análise do comportamento e o behaviorismo radical. Foi possível também promover um panorama sobre as contingências comportamentais nas quais os atletas estão inseridos, assim como apresentar as intervenções psicológicas que estão sendo 
praticadas atualmente no Brasil. A partir disso, abrem-se oportunidades para que sejam desenvolvidos trabalhos que preencham possíveis lacunas e possibilitem o desenvolvimento e a sistematização dessa ciência aplicada.

A concepção de atleta aqui adotada refere-se a praticantes de diversas modalidades esportivas, coletivas ou individuais. O esporte é uma atividade competitiva, que envolve um esforço físico e vigoroso e/ou o uso de habilidades complexas e específicas, e cuja motivação para a prática está em fatores intrínsecos e extrínsecos. Trata-se de um fenômeno social e cultural, e, portanto, está sujeito a sofrer influências dessas esferas (BARBANTI, 2006). Existem outros contextos de prática de atividade física com fins educativos, recreativos ou de reabilitação, porém, nesses casos não há competitividade, nem o foco em aprimoramento de habilidades específicas para melhora do desempenho na atividade. Em vez disso, visam aliviar estresse, promover saúde, bem-estar, aprimoramento estético ou adaptação e reabilitação após algum trauma (CILLO, 2012).

A partir dessas delimitações, pode-se pensar nos desdobramentos psíquicos e comportamentais que a prática esportiva pode acarretar para um indivíduo. Surgem questionamentos como: de que modo o esforço físico, a especificidade motora, a pressão social, os relacionamentos interpessoais, a cultura e questões relacionadas a eventos privados (pensamentos e emoções) podem influenciar e determinar a prática esportiva e o desempenho de um atleta?O presente artigo propõe-se a identificar a situação em que os atletas encontram-se quando estão em estados patológicos de estresse e/ou ansiedade e quais são os fatores ambientais (antecedentes) e os eventos públicos (aqueles que podem ser constatados por mais de um observador) e privados (pensamentos e emoções) presentes e reconhecidos como eliciadores de sintomas e evocadores de repertórios de estresse e ansiedade. Para tanto, primeiramente serão delimitados os conceitos de ansiedade e estresse a fim de, posteriormente, contextualizar esses quadros dentro de ambientes esportivos diversos.

Grünspun (1966) argumenta que todos os seres humanos sofrem, desde o nascimento, de um certo grau de ansiedade inevitável que será capaz de prepará-los para suportar a ansiedade comum que a vida lhes causará. Em 1979, Spielberger definiu a ansiedade como uma reação emocional ante o estresse, caracterizando-a por nervosismo, preocupação e apreensão que podem ser gerados por pensamentos (ansiedade cognitiva) ou reações físicas (ansiedade somática). Trata-se de um estado complexo, de uma condição psicológica do organismo humano, constituída por propriedades fenomenoló- 
gicas e fisiológicas que se diferenciam de estados emocionais como estresse, ameaça e medo, pois tais eventos se apresentam como possíveis causadores do estado de ansiedade (SPIELBERGER, 1979). Cozzani et al. (1997) descrevem como característica um sentimento de insegurança causado pela expectativa de algum perigo, ameaça ou desafio existente.

Diversos autores reconhecem a existência de dois tipos de manifestação da ansiedade: ansiedade-traço e ansiedade-estado (SANTOS; PEREIRA, 1997; GONÇALVES; BELO, 2007). A ansiedade-traço (A-traço) seria uma tendência comportamental na qual uma pessoa vê as situações como potencialmente perigosas e/ou ameaçadoras à sua vida ou ao seu bem-estar, logo, estaria relacionada a um traço de personalidade. A ansiedade-estado (A-estado) é caracterizada como um episódio emocional transitório causado por algum evento - ou situação - específico. Em geral, espera-se que indivíduos com altos níveis de A-traço demonstrem também elevações quanto à A-estado, já que apresentam uma tendência a observar as situações como ameaçadoras. Porém, se a circunstância for percebida como não ameaçadora, o indivíduo reage com A-estado baixa (SPIELBERGER, 1972). O nível de A-estado do indivíduo (independentemente da A-traço) irá depender do grau em que a situação específica é percebida como perigosa/ameaçadora, e isso terá forte influência da história comportamental do indivíduo (BIAGGIO; NATALÍCIO; SPIELBERGER, 1977).

Segundo o referencial teórico da análise do comportamento, a ansiedade define-se como um episódio emocional, havendo interação entre comportamentos respondentes (taquicardia, sudorese, falta de ar etc.) e comportamentos operantes (fuga e esquiva de estímulos aversivos condicionados e incondicionados). Podem ainda existir outros comportamentos operantes no mesmo momento em que o estímulo aversivo é apresentado, ocasionando o emparelhamento desses estímulos. Tal acontecimento pode propiciar que um estímulo, a princípio neutro, torne-se um pré-aversivo, ou seja, um estímulo que inicialmente não produzia nenhuma resposta negativa no organismo passa a possuir função aversiva condicionada (BORGES; CASSAS, 2011).

De acordo com Borges e Cassas (2011, p. 46),

\footnotetext{
Para um analista do comportamento, a ansiedade não seria aquilo que ocorre dentro da pele do sujeito, mas sim toda a relação que envolve tanto a situação "ansiógena" quanto as alterações no repertório do sujeito produzidas nessa situação.
} 
Sonstroem (1984) afirma que a ansiedade tem sido estudada no esporte partindo de seus efeitos emocionais negativos, entretanto, a partir de estudos realizados em fisiologia e psicologia, tem-se demonstrado que é necessário um determinado tipo e magnitude de ansiedade para a prontidão na execução de algumas tarefas.

De acordo com Becker Junior (2000) e Weinberg e Gould (2001), a influência da ansiedade sobre o desempenho está relacionada à Teoria do U Invertido. Segundo essa proposta, conforme o aumento da ansiedade, há uma facilitação do desempenho até um ponto ideal máximo e ansiedade moderada. Após esse ponto, caso a ansiedade continue aumentando, o desempenho passa a declinar.

Níveis moderados de ansiedade são vistos como ideais para um desempenho adequado, uma vez que a atenção do atleta tem seu foco direcionado para uma tarefa específica. Isso impede que ele se distraia com situações irrelevantes (baixa ansiedade) ou diminua seu campo de visão, prejudicando seu desempenho (alta ansiedade), tendo, portanto, as alterações fisiológicas necessárias com a ausência de ações negativas no seu campo de percepção cognitiva (LEITE et al., 2011; BERTUOL; VALENTINI, 2006). É importante ressaltar que cada tarefa requer um nível de ansiedade ótimo diferente e que as diferenças individuais também devem ser levadas em consideração (ALEXANDRE, 2010).

O estresse é frequentemente citado por alguns autores como a "doença" dos tempos modernos (COUTO, 1987; MOLINA, 1996; SOUZA; MARIANI; SAMULKI, 2010). Pode ser definido como qualquer situação de tensão aguda ou crônica que produz uma mudança no comportamento físico e/ou no estado emocional do indivíduo. Trata-se, portanto, de uma reação do organismo à necessidade de uma grande adaptação a um evento ou situação de importância (SOUZA; MARIANI; SAMULKI, 2010). Essa reação emocional acontece quando o ambiente é percebido como exigente demais ou excedente a seus recursos pessoais de enfrentamento, sendo ameaçador de seu bem-estar (LAZARUS; FOLKMAN, 1984).

Em situações de estresse, nosso corpo encontra-se fora do estado do equilíbrio homeostático, emitindo respostas filogenéticas reflexas em busca de retomar esse equilíbrio. Para isso, é necessário um gasto de energia extra que gera desgaste físico e mental. Quando possuímos estratégias de enfrentamento e conseguimos utilizá-las nas situações de estresse, restabelecemos a ho- 
meostase. O tempo e a energia utilizados nessas fases vão depender de fatores como: o desenvolvimento prévio de estratégias de enfrentamento, o impacto que o estímulo estressor tem no indivíduo e a capacidade de fazer uso das técnicas de enfrentamento. $\mathrm{O}$ estresse crônico e muito intenso acontece quando essas etapas descritas não acontecem de forma satisfatória e o estímulo estressor continua presente por tempo prolongado (LIPP, 2000). Esse estado de estresse crônico e incapacitante é chamado de síndrome de burnout (VERARDI et al., 2012).

No âmbito esportivo, o estresse pode ser causado por fatores relacionados à prática esportiva ou pessoais. Essas condições produzem consequências negativas, como: aumento da fadiga, dores, angústia, ansiedade, depressão, diminuição do desempenho intelectual, desorientação espaçotemporal, atenção dispersa, impossibilidade de relaxamento, alterações do estado de alerta, tensão muscular facial e mandibular e respostas desproporcionais aos estímulos externos (LEITE et al., 2011). Em modalidades coletivas, o estresse pode promover redução da qualidade de comunicação e tomada incorreta de decisões (SILVA; ENUMO, 2016b).

O estresse pré-competitivo é mais comumente descrito nos estudos, sendo caracterizado pela antecipação da competição, das oportunidades, dos riscos e das consequências que estão nela envolvidos (ROSE JUNIOR, 2002). Entretanto, estudos discutem a necessidade de certo nível de estresse para se garantir o melhor desempenho. Vários modelos vêm sendo propostos para explicar a manutenção e o aperfeiçoamento de capacidades funcionais e do conhecimento dos próprios limites (MACHADO, 1997).

O trabalho do psicólogo realiza-se na perspectiva de desenvolver aspectos como: equilíbrio emocional, concentração/foco, tolerância a frustrações, desempenho sob pressão, autoconfiança, motivação, respeito, inteligência tática, disciplina e espírito de luta (VORKAPIC, RANGÉ, 2014). Além dessas habilidades relacionadas ao âmbito esportivo, é necessário que o psicólogo esteja atento a possíveis fatores da vida pessoal do atleta que possam afetar seu desempenho. É importante enfatizar que as demandas do time ou atleta serão variadas e dinâmicas, exigindo flexibilidade e criatividade por parte do profissional de psicologia para identificar e trabalhar com essas demandas.

Tendo esses conceitos iniciais como base, o objetivo desta pesquisa também foi compreender como são realizadas as intervenções psicológicas em casos de ansiedade e estresse em atletas, buscando, em bases de dados sele- 
cionadas, o que existe de artigos científicos publicados em periódicos brasileiros sobre o tema. São objetivos específicos: compreender quais são os estímulos antecedentes evocadores de sintomas de estresse e ansiedade em atletas; descrever quais são as técnicas utilizadas para diagnóstico desses sintomas e os tipos de intervenção utilizados; e apresentar intervenções comportamentais já registradas na produção científica brasileira pertinente.

\section{MÉTODO}

Este trabalho consistiu em uma revisão bibliográfica de caráter exploratório e explicativo. Buscaram-se artigos científicos nos quais estivessem expressas as formas de intervenção mais eficazes para tratar a ansiedade e o estresse em esportistas.

Para tanto, realizou-se a seleção de artigos científicos publicados em periódicos brasileiros, entre os anos de 2010 e 2017, nas seguintes bases de dados: PubMed, Google Acadêmico, SciELO, PePSIC e Bireme.

Nas bases de dados, foram buscadas as seguintes palavras-chave: psicologia, esporte, técnicas, ansiedade, estresse, relaxamento e intervenções psicológicas, nas seguintes combinações: intervenções psicológicas e esporte; estresse e esporte; ansiedade e esporte; relaxamento e esporte; técnicas e psicologia e esporte; estresse e ansiedade e esporte; técnicas e estresse e esporte; técnicas e ansiedade e esporte. Os critérios de exclusão utilizados foram: publicações estrangeiras; fora do período preestabelecido; estudos com foco em outras disciplinas (estresse oxidativo, alterações cardiológicas ou respiratórias, entre outros parâmetros bioquímicos e fisiológicos); avaliações de árbitros e/ou treinadores; e estudos sobre benefícios da atividade física em populações clínicas.

A primeira seleção de artigos foi realizada utilizando filtros nas próprias bases de dados e a leitura dos resumos dos artigos, tendo sido selecionados 62 artigos que foram lidos na íntegra. Excluíram-se produções que, após a leitura, não apresentavam relação com nenhum dos objetivos propostos e/ou estavam dentro de um dos critérios de exclusão já apresentados. Ao final da seleção, analisaram-se 44 artigos científicos.

\section{DISCUSSÃO DE RESULTADOS}

A análise dos dados foi realizada simultaneamente à coleta, portanto, durante a leitura dos artigos selecionados, realizaram-se destaques e anota- 
ções. Tal processo possibilitou a organização e o agrupamento em categorias, visando apresentar um panorama do que há da produção científica brasileira na área. O procedimento de análise se deu de acordo com o seguinte esquema: "Transcrição das anotações obtidas na coleta de dados $\rightarrow$ procura de categorias e pautas (temas) $\rightarrow$ destaque e seleção dos dados $\rightarrow$ elaboração de esquema de análise (re-sequência)" (FIELDING, 1993, p. 163).

Ao longo da coleta de dados, identificaram-se diferentes instrumentos de avaliação citados como ferramentas para a detecção da intensidade de estresse e ansiedade nos esportistas: 1. Competitive State Anxiety Inventory 2 (CSAI-2); 2. Inventário de Ansiedade Traço-Estado (Idate); 3. Inventário de Stress no Futebol (ISF); 4. Sport Competition Anxiety Test (Scat); 5. Questionário de Estresse e Recuperação para Atletas (Recovery-Stress Questionnaire for Athletes - RESTQ-Sport); 6. Inventário de Ansiedade de Beck (Beck Anxiety Inventory - BAI); 7. Daily Analysis of Life Demands for Athletes (Dalda); 8. Teste de Estresse Psíquico para Voleibol (TEP-V); 9. Lista de Sintomas de Stress Pré-Competitivo Infanto-Juvenil (LSSPCI); 10. Escala de Ansiedade, Depressão e Estresse (Eads-21); e 11. Maslach Burnout Inventory (MBI). Mais adiante serão discutidos os resultados de cada um dos estudos e comentados os testes utilizados, lembrando que o presente estudo focará a análise dos artigos e suas contribuições.

As publicações selecionadas foram organizadas (Tabela 1) de acordo com seus objetivos em três categorias: antecedentes (artigos que buscam compreender quais são os fatores eliciadores de sintomas de estresse e ansiedade); diagnóstico (artigos que utilizam instrumentos de avaliação e realizam a descrição das situações de estresse e ansiedade); e intervenção (artigos que investigam atividades que visam ao controle ou à melhora dos sintomas de estresse e ansiedade, ou estratégias de controle e compensação).

Na categoria antecedentes, analisaram-se 14 artigos; em diagnóstico, 24; e, em intervenção, seis. As produções, por vezes, contemplaram mais do que uma categoria de análise, portanto seus resultados serão apresentados separadamente na categoria correspondente.

Foram selecionados ainda quatro artigos que descrevem possíveis fatores de proteção, ou seja, fatores que podem auxiliar os atletas na prevenção de situações de estresse/ansiedade, também descrevendo os ganhos obtidos a partir de uma vida de prática esportiva de alto rendimento e competições. Esses dados serão apresentados na seção "Considerações finais" deste artigo. 
Tabela 1 Descrição das categorias de análise criadas e o número de artigos utilizados em cada categoria

\begin{tabular}{llc}
\hline Categoria & \multicolumn{1}{c}{ Descrição } & Número de artigos \\
\hline Antecedente & $\begin{array}{l}\text { Artigos que apresentam fatores eliciadores de estresse } \\
\text { e ansiedade. }\end{array}$ & 14 \\
\hline Diagnóstico & $\begin{array}{l}\text { Artigos que apresentam instrumentos de avaliação } \\
\text { e descrevem situações de estresse e ansiedade. }\end{array}$ & 24 \\
\hline \multirow{2}{*}{ Intervenção } & $\begin{array}{l}\text { Artigos que apresentam as atividades que visam ao } \\
\text { controle ou à melhora do estresse e da ansiedade, } \\
\text { e as estratégias de controle e compensação. }\end{array}$ & 6 \\
\hline
\end{tabular}

Fonte: Elaborada pelos autores.

\section{RESULTADOS}

Desde o processo de coleta, organização e categorização dos dados, foi possível notar que a maioria da produção científica está voltada para o diagnóstico de situações de estresse/ansiedade, e, muitas vezes, os fatores antecedentes e as intervenções são apresentados apenas com referências teóricas de outras pesquisas. De fato, muitos artigos possuíam em suas considerações finais sugestões de que fossem realizadas outras pesquisas empíricas no sentido de compreender os fatores desencadeantes de estresse/ansiedade e de elaborar intervenções tanto para prevenção como para desenvolvimento de autocontrole e autoconhecimento. Identifica-se, portanto, uma inicial necessidade no desenvolvimento de produções científicas que deem primazia à compreensão dos estímulos antecedentes do estresse e da ansiedade, bem como melhor descrição das intervenções.

\section{Antecedentes}

Na categoria antecedentes, analisaram-se oito artigos de estudos empíricos e seis artigos de revisão da literatura. Foram encontrados mais estudos sobre estresse, com diferentes modalidades esportivas, de modo que alguns fatores descritos estavam relacionados mais intimamente à modalidade pesquisada. Entretanto, de forma geral, foram descritos fatores inerentes à prática esportiva e à competição e fatores adjacentes à situação esportiva.

No caso de um estudo com velejadores, apontaram-se como estímulos eliciadores de estresse: problemas no barco, desorganização da equipe, indecisão quanto à tripulação, relação com a tripulação, perder regatas, pre-start 
das regatas e juiz (SEGATO et al., 2010). Os estímulos adjacentes à competição foram: vestibular/faculdade, conciliar o trabalho à vela, problemas financeiros, problemas familiares, gerenciamento de tempo, saudade de casa e adaptação ao novo (SEGATO et al., 2010).

Em atletas adultos de voleibol, Balbim, Nascimento Junior e Vieira (2012) utilizaram o instrumento TEP-V para avaliar o estresse pré-competitivo. Os fatores desencadeantes encontrados foram: condicionamento físico inadequado, preparação técnico-tática inadequada, falta de preparação psicológica, conflitos com os companheiros, entrar no jogo machucado, machucar-se durante o jogo, nervosismo excessivo, errar jogadas no início do jogo, errar jogadas no final do jogo, dormir mal na noite anterior, conflitos com o treinador ou com familiares, ser prejudicado pelo árbitro, instalações e condições de jogo inadequadas (BALBIM; NASCIMENTO JUNIOR; VIEIRA, 2012).

Por fim, outros três artigos utilizaram a escala LSSPCI em escolares, e os sintomas mais comumente reportados foram: fico empolgado, sonho com a competição, fico nervoso, fico preocupado com o resultado da competição, não vejo a hora de competir, fico ansioso, tenho medo de cometer erros (PIZZI; BARRETA; GRIGOLLO, 2016). Em atletas de handebol, avaliaram-se as possíveis diferenças entre os sexos, e os autores encontraram diferenças estatisticamente significativas apenas no sintoma sonho com a competição, mais vezes reportado por meninos (CAPUTO; ROMBALDI; SILVA, 2014). Em atletas de futebol da categoria sub-17, a situação que apresentou maiores índices para ser motivadora de estresse foi o "medo de competir mal", e, com relação a sintomas físicos, foi relatado "suo bastante" e "minha boca fica seca" (SOUZA; COSTA, 2017). Vale ressaltar que parte desses sintomas pode estar intimamente relacionada com a fase de desenvolvimento em que esses indivíduos se encontram, a adolescência, e, portanto, pode não ter caráter patológico.

Em artigos de revisão, foi encontrado que o estresse é causado de forma geral por fatores que podem ser interpessoais e/ou situacionais (LEITE et al., 2011). Em atletas de modalidade coletiva (SILVA; ENUMO, 2016b), encontraram-se os seguintes fatores: relação com o treinador, condição física do atleta, nível de rendimento, desconhecimento sobre o adversário, exigências externas, altas cargas de treinamento, novas responsabilidades e cobranças na vida pessoal e em modalidades coletivas. Esse estudo constatou que o atleta em boas condições físicas teria menores níveis de estresse, uma vez que "entrar no jogo machucado" ou "machucar-se durante o jogo" foram avaliados como fatos que desencadeiam sintomas de estresse. Os autores também reportam 
que o nível de rendimento exigido pode ser um potencial fator estressante e de pressão por bons resultados, o que pode gerar conflitos entre os membros do time (SILVA; ENUMO, 2016a).Em bailarinos, foram relatados fatores muito semelhantes, a saber: interação bailarino-coreógrafo; condições físicas, uma vez que lesões levam à insegurança; e relacionamento com o companheiro de grupo (SILVA, 2012).

Com relação aos potenciais preditores psicológicos de lesão, um estudo realizado com jogadores de futebol de 17 a 19 anos apontou os seguintes fatores: deixar o lar, pressão dos pais quanto ao rendimento na escola e no esporte e construção de uma rede social (RIBEIRO; OLIVEIRA; SILVA, 2013). Para atletas mais velhos, relataram-se: construção de relacionamentos e planejamento de carreira (RIBEIRO; OLIVEIRA; SILVA, 2013). O estudo aponta ainda que, independentemente da idade e do sexo dos atletas, fatores como morte na família, mudanças de relacionamento e transições da vida podem predispor à ocorrência de lesões (RIBEIRO; OLIVEIRA; SILVA, 2013). É importante ressaltar que muitos desses fatores isolados não se caracterizam como estressores ou preditores de lesões. É preciso analisar a interpretação que o atleta atribui a determinada situação e os recursos de enfrentamento que possui para lidar com ela: "o aumento do estresse ocorre principalmente quando as demandas de uma situação excedem os recursos para responder a essas exigências" (RIBEIRO; OLIVEIRA; SILVA, 2013, p. 74).

Outro tema recorrente em artigos de revisão é a síndrome de burnout, entendida como uma reação ao estresse crônico. Como síndrome, tem sinais e sintomas físicos, mentais e comportamentais, sendo a característica principal o esgotamento psíquico e emocional (PIRES; BRANDÃO; MACHADO, 2005). As causas encontradas para o aparecimento dessa síndrome são: ansiedade em relação ao próprio desempenho, ausência de feedback, dificuldade para conciliar o esporte com outras atividades e déficit no suporte social formal e/ou informal (VERARDI et al., 2012).

Quando um estressor é percebido como ameaçador, sem a presença de uma ameaça real e objetiva, uma reação emocional é evocada e respostas ansiosas são emitidas. Nesse sentido, Leite et al. (2011) encontraram uma relação inversamente proporcional entre nível de autoconfiança e ansiedade ou percepção de ameaça sobre eventos competitivos relacionados à dança, ou seja, quanto maior for o nível de autoconfiança do atleta, menor será sua percepção de ameaça ou perigo iminente, e, portanto, as respostas consideradas ansiosas têm menor probabilidade de ocorrer. As situações apontadas como 
fatores que auxiliam nas mudanças de níveis ansiosos são: situações de risco, que envolvem colisão, queda, erros de coreografia e imprevistos com acessórios e figurinos; presença da plateia e avaliadores; companheiro; exposição à avaliação social em ambiente desconhecido; distância de casa; e recompensas extrínsecas disponíveis (premiação) (LEITE et al., 2011).

Em estudo empírico com jogadoras de voleibol, a escala CSAI-2 foi aplicada e os resultados apontaram como fatores desencadeantes de ansiedade: expectativa e presença de terceiros, falta de habilidade e qualidade superior do time adversário (FERREIRA et al., 2014).

No que tange aos antecedentes, independentemente da modalidade estudada, existem fatores que são inerentes à prática esportiva e fatores que dizem respeito à vida pessoal dos atletas. Sobre os fatores inerentes ao esporte, destacam-se questões relacionais (companheiros, técnicos e torcida) e questões relativas à demanda de exercício exigida, seja em treinamentos ou durante campeonatos. Sendo assim, ambos os tipos de fatores eliciadores de estresse/ansiedade irão intervir no nível de concentração e no desempenho competitivo. Logo, é importante que o atleta possua inteligência emocional (PAYNE, 1986), que envolve não apenas ter conhecimento sobre seus sentimentos e suas reações emocionais (o que promove autoconfiança), mas também possuir recursos para lidar com essas situações. O desenvolvimento de tal habilidade também visa evitar que a demanda não exceda a capacidade individual de coping, ou seja, que a demanda não esteja além das estratégias de adaptação a circunstâncias adversas que o indivíduo possui em seu repertório comportamental (ANTONIAZZI; DELL'AGLIO; BANDEIRA, 1998).

\section{Diagnóstico}

Na Quadro 1, podemos observar os resultados obtidos a partir de pesquisas empíricas sobre ansiedade em atletas de diversas modalidades esportivas, assim como os instrumentos de avaliação utilizados.

Concernente às pesquisas realizadas com a aplicação do CSAI-2 em atletas de voleibol, foi relatado que o nível de ansiedade pode alterar: o desempenho nas competições, a habilidade de realizar os fundamentos técnicos com precisão e a autoconfiança dos profissionais (SILVA et al., 2014). Em atletas infantojuvenis da mesma modalidade, foi encontrado um índice de ansiedade geral menor em meninos e maior autoconfiança, se comparado às meninas (MACHADO et al., 2016). Entre o sexo feminino, as atletas titulares apresen- 
taram maior índice de autoconfiança do que as reservas (MACHADO et al., 2016), provavelmente por causa da certeza de que irão jogar. Outro estudo com atletas de uma equipe infantil feminina relata oscilações nos níveis de ansiedade ao longo da competição (ZANETTI; MACHADO, 2010), com aumento considerável nos componentes cognitivos e somáticos, acompanhado de uma diminuição da autoconfiança (SONOO et al., 2010). Uma das possíveis explicações para esse fato é o nível da expectativa que as atletas possuem com relação ao resultado. Essa expectativa (ansiedade cognitiva) interfere no desempenho e na autoeficácia do esportista, o que pode levar a somatizações dos resultados ao longo da competição (ansiedade somática) (ZANETTI; MACHADO, 2010; VIEIRA et al., 2011).

Entretanto, em dois estudos que utilizaram o mesmo instrumento de avaliação - em jogadores de handebol e em modalidades esportivas coletivas e individuais - (BARBOSA; SEABRA; CALGARO, 2011; ALEXANDRE, 2010), não se observou correlação entre ansiedade e desempenho. Esses resultados podem representar: ausência dessa correlação, falta de habilidade dos pesquisadores na coleta e análise de dados ou insensibilidade do instrumento.

É válido ressaltar que Alexandre (2010) encontrou um maior nível de ansiedade cognitiva em modalidades individuais, se comparado às coletivas. Contudo, deve-se levar em consideração que, na amostra coletada, a modalidade coletiva estava jogando em casa e a modalidade individual não, portanto pode haver influência do fenômeno home advantage (NEVIL; HOLDER, 1999).

O estudo que utilizou apenas o instrumento Scat para avaliação de atletas jovens (INTERDONATO et al., 2010) encontrou diferença significativa entre modalidades individuais e coletivas, sendo mais elevados os níveis de ansiedade nos atletas de modalidades individuais. Uma possível explicação para esse achado é que, em modalidades coletivas, há uma distribuição da responsabilidade diante do resultado da competição, enquanto na modalidade individual, toda a atenção e as expectativas de terceiros estão depositadas apenas em um atleta (INTERDONATO et al., 2010).

Quanto às pesquisas que utilizaram a escala Idate, apenas o estudo com universitários encontrou diferença nos escores de ansiedade entre sexos (LEITE et al., 2016). Todavia, todos relatam níveis consideráveis de ansiedade pré-competição (LEITE et al., 2016; PEREIRA et al., 2014; CONSTANTINO; PRADO; PRADO, 2010). 


\section{Quadro 1 Resultados encontrados em pesquisas empíricas sobre ansiedade}

\begin{tabular}{|c|c|c|}
\hline Título do artigo & Resultados obtidos & Instrumento \\
\hline $\begin{array}{l}\text { Ansiedade estado } \\
\text { pré-competitiva em } \\
\text { atletas de voleibol } \\
\text { infanto-juvenis } \\
\text { (MACHADO et al., 2016) }\end{array}$ & $\begin{array}{l}\text { Sexo masculino: maior nível de autoconfiança e } \\
\text { menor índice de ansiedade geral. } \\
\text { Sexo feminino: titulares possuem maior } \\
\text { autoconfiança se comparados aos reservas. Não } \\
\text { há diferença, quanto a sintomas de ansiedade, } \\
\text { entre jogos dentro e fora de casa. }\end{array}$ & CSAI-2 \\
\hline $\begin{array}{l}\text { Ansiedade e } \\
\text { desempenho de } \\
\text { jogadores de voleibol em } \\
\text { partidas realizadas } \\
\text { dentro e fora de casa } \\
\text { (SILVA et al., 2014) }\end{array}$ & $\begin{array}{l}\text { Encontraram relação inversamente proporcional } \\
\text { entre ansiedade e habilidades técnicas } \\
\text { específicas da modalidade: quanto maior a } \\
\text { ansiedade, pior o desempenho dos fundamentos } \\
\text { do vôlei. } \\
\text { * Time com acompanhamento psicológico, } \\
\text { praticantes há pelo menos cinco anos e ótimo } \\
\text { histórico no campeonato. }\end{array}$ & $\begin{array}{c}\text { CSAI-2 } \\
\text { BAI }\end{array}$ \\
\hline $\begin{array}{l}\text { Ansiedade e } \\
\text { desempenho: um estudo } \\
\text { com uma equipe infantil } \\
\text { de voleibol feminino } \\
\text { (SONOO et al., 2010) }\end{array}$ & $\begin{array}{l}\text { Ansiedade-estado equilibrada na fase } \\
\text { preparatória. } \\
\text { Ansiedade-estado alterada no componente } \\
\text { cognitivo na fase competitiva (com duas } \\
\text { derrotas). Conclui-se que a ansiedade pode } \\
\text { alterar o desempenho das atletas em situação } \\
\text { competitiva. }\end{array}$ & $\begin{array}{c}\text { CSAI-2 } \\
\text { Scat }\end{array}$ \\
\hline
\end{tabular}

Comportamento no nível
de ansiedade de atletas
de futsal nos jogos
regionais de Atibaia -
2009 (ZANETTI;
MACHADO, 2010)

Autoeficácia e nível de ansiedade em atletas jovens do atletismo paranaense (VIEIRA et al., 2011)

Nível moderado de ansiedades cognitiva e somática, com variações ao longo do campeonato.

Ansiedade cognitiva maior na estreia e ansiedade somática maior em jogo de eliminatória.

Atletas com altas expectativas de resultado apresentam maiores níveis de ansiedades cognitiva e somática e de autoconfiança. As crenças cognitivas (expectativas) dos atletas têm interferência na autoeficácia (resultado), levando à somatização do sucesso e fracasso.

\begin{tabular}{clc}
\hline Validade de testes de & Não foi encontrada relação entre ansiedade e & \\
atenção e ansiedade na & atenção. & CSAI-2 \\
predição do desempenho & Não foi encontrada relação entre ansiedade e & Trilhas B \\
no handebol (BARBOSA; & desempenho no esporte. & Cancelamento \\
SEABRA; CALGARO, 2011) & &
\end{tabular}


Quadro 1 Resultados encontrados em pesquisas empíricas sobre ansiedade (continuação)

\begin{tabular}{|c|c|c|}
\hline Título do artigo & Resultados obtidos & Instrumento \\
\hline $\begin{array}{l}\text { Análise da ansiedade } \\
\text { traço competitiva em } \\
\text { jovens atletas } \\
\text { (INTERDONATO et al., } \\
\text { 2010) }\end{array}$ & $\begin{array}{l}\text { Não apresentaram escores altos de ansiedade- } \\
\text {-traço. } \\
\text { Encontraram diferença significativa nos níveis de } \\
\text { ansiedade entre modalidades individuais e } \\
\text { coletivas. }\end{array}$ & Scat \\
\hline $\begin{array}{l}\text { Representações de } \\
\text { ansiedade e medo de } \\
\text { atletas universitários } \\
\text { (LEITE et al., 2016) }\end{array}$ & $\begin{array}{l}\text { Escores femininos de reações de ansiedade e } \\
\text { medo pré-competição foram maiores que os } \\
\text { masculinos. De modo geral, os níveis de } \\
\text { ansiedade variaram de leve a moderado, e os } \\
\text { escores de medo foram bem baixos. Bailarinos } \\
\text { que possuem ansiedade-traço mais elevada } \\
\text { tendem a ter índices mais altos de ansiedade- } \\
\text {-estado pré e pós-competição. }\end{array}$ & $\begin{array}{l}\text { Idate } \\
\text { Questionário } \\
\text { de estado } \\
\text { emocional } \\
\text { (QEE) }\end{array}$ \\
\hline $\begin{array}{l}\text { Nível de ansiedade em } \\
\text { bailarinos pré e } \\
\text { pós-competição } \\
\text { (PEREIRA et al., 2014) }\end{array}$ & $\begin{array}{l}\text { Relação inversamente proporcional entre índice } \\
\text { de massa corporal (IMC) e nível de ansiedade } \\
\text { pós-competição. } \\
\text { Praticantes de outras atividades físicas } \\
\text { apresentam menores níveis de ansiedade-traço } \\
\text { do que não praticantes. Não há correlação entre } \\
\text { ansiedade e idade, sexo, diferentes modalidades } \\
\text { de dança e a presença ou não de lesão. }\end{array}$ & Idate \\
\hline $\begin{array}{l}\text { Ansiedade em bailarinos } \\
\text { profissionais nas } \\
\text { apresentações de dança } \\
\text { (CONSTANTINO; } \\
\text { PRADO; PRADO, 2010) }\end{array}$ & $\begin{array}{l}\text { Maiores níveis de ansiedade (estado e traço) } \\
\text { antes da apresentação do que depois. Não foi } \\
\text { encontrada relação entre ansiedade e idade, } \\
\text { gênero e tempo de experiência. }\end{array}$ & Idate \\
\hline
\end{tabular}

Fonte: Elaborado pelos autores.

O Quadro 2 apresenta os estudos empíricos sobre estresse. As pesquisas que utilizaram o instrumento RESTQ-Sport observaram que os níveis de estresse aumentam em situações de treinamento, se comparadas a situações de recuperação/folga (NOCE et al., 2011), porém sem alterações em diferentes situações de treinamento (MATOS et al., 2014). Em um estudo sobre o efeito de dias consecutivos de competições, observaram-se menor índice de recuperação física e maior índice de lesão no pós-competição, além de uma diferença maior entre esforço exigido e recuperação (FREITAS et al., 2014). Em estudo com nadadores durante uma temporada de competições, não houve 
diferença significativa entre os dados obtidos antes, durante e depois desse período, mas a diferença estresse-recuperação foi qualitativamente maior no meio da temporada (NOGUEIRA et al., 2015). Esses dados, somados a observações de desempenho ao longo do campeonato, indicam que competições esportivas que não preveem dias para recuperação do atleta acabam comprometendo o desempenho esportivo dele (FREITAS et al., 2014).

Com esportistas lesionados, destaca-se a importância de ênfase em fatores positivos de recuperação para que esses sobressaiam em relação aos aspectos negativos e colaborem para o retorno à prática esportiva (AKAMINE et al., 2016).

De modo geral, é importante considerar o tempo de recuperação/repouso dos atletas para que obtenham o melhor desempenho tanto no treinamento quanto na competição e para que sejam evitados sintomas de estresse que podem ocasionar lesões, além de esgotamento físico e psíquico, que, em última instância, levam à síndrome de burnout (VERARDI et al., 2012).

Dois estudos procuraram relação entre diferentes cargas de treinamento e tolerância ao estresse em ginastas, jogadores de basquetebol e de voleibol (FREITAS et al., 2013; MOREIRA et al., 2010). Na avaliação da tolerância ao estresse, Freitas et al. (2013) e Moreira (2010) utilizaram o instrumento Dalda e constataram que quanto maiores são as cargas de treinamento, menor é a tolerância ao estresse, com os atletas reportando "cansaço" e "necessidade de descanso". Ademais, apontou-se um aumento nas fontes de estresse que não foram descritas nos dois estudos.

Já o estudo que utilizou a Escala de Estresse Percebido relata níveis maiores de estresse pré-competição, se comparados ao pós, e menores índices de estresse em atletas mais experientes, sugerindo que o tempo de prática auxilia no controle de reações emocionais prejudiciais ao desempenho (SEGATO et al., 2010).

Quadro 2 Resultados encontrados em pesquisas empíricas sobre estresse

\begin{tabular}{lll}
\hline \multicolumn{1}{c}{ Título do artigo } & \multicolumn{1}{c}{ Resultados obtidos } & Instrumento \\
\hline $\begin{array}{l}\text { Análise dos sintomas de } \\
\text { overtraining durante os }\end{array}$ & $\begin{array}{l}\text { Todos os indicadores de estresse } \\
\text { aumentaram no período de treinamento. }\end{array}$ & \\
$\begin{array}{l}\text { períodos de treinamento e } \\
\text { de umeração: estudo de caso }\end{array}$ & Alguns fatores de recuperação apontaram & Reminina da \\
$\begin{array}{l}\text { Superliga de Voleibol } \\
\text { baixo nível de eficácia, a saber: sucesso, }\end{array}$ & aceitação pessoal, autoeficácia e \\
\hline
\end{tabular}




\section{Quadro 2 Resultados encontrados em pesquisas empíricas sobre estresse \\ (continuação)}

Título do artigo

Cargas elevadas de

treinamento alteram funções

cognitivas em jogadores de

futebol (MATOS et al., 2014)
Resultados obtidos

Instrumento

Altas cargas de treinamento causam

lentificação psicomotora. Não houve

alteração na percepção de estresse em

RESTQ-Sport

diferentes situações de treinamento.

De acordo com esse estudo, atletas com

nível maior de valores tranquilizantes e níveis

estressantes baixos relataram alguns

Estresse e lesões em atletas aspectos negativos (desconforto em

de esportes coletivos

situações de pressão esportiva, medo de se

(AKAMINE et al., 2016)

lesionar e preocupação com o retorno às

RESTQ-Sport

Questões

abertas competições), mas os aspectos positivos sobressaíram, o que contribui para o processo de recuperação das lesões.

Efeito de quatro dias consecutivos de jogos sobre a potência muscular, estresse e recuperação percebida, em jogadores de futsal (FREITAS et al., 2014)

Influência das cargas de treinamento sobre o rendimento e os níveis de recuperação em nadadores (NOGUEIRA et al., 2015)
"Recuperação física": maior índice pré-competição.

"Lesões": maior índice pós-competição. RESTQ-Sport Maior diferença entre esforço e recuperação na situação pós-competição.

O instrumento foi aplicado no começo da temporada de campeonatos, no meio e no final. O segundo momento apresentou diferença maior entre estresse e RESTQ-Sport recuperação, porém não estatisticamente significativa.

Aumento das fontes de estresse devido ao aumento da carga interna de treinamento. Dalda As fontes não são descritas. em jovens ginastas (ANTUALPA et al., 2015)

Carga interna, tolerância ao estresse e infecções do trato respiratório superior em atletas de basquetebol Relação inversamente proporcional entre carga interna de treinamento e tolerância Dalda

(FREITAS et al., 2013) ao estresse. 
Resultados encontrados em pesquisas empíricas sobre estresse

(continuação)

\begin{tabular}{|c|c|c|}
\hline Título do artigo & Resultados obtidos & Instrumento \\
\hline $\begin{array}{l}\text { Percepção de esforço da } \\
\text { sessão e a tolerância ao } \\
\text { estresse em jovens atletas } \\
\text { de voleibol e basquetebol } \\
\text { (MOREIRA et al., 2010) }\end{array}$ & $\begin{array}{l}\text { Não houve diferença nas fontes de estresse. } \\
\text { Maiores sintomas de estresse em cargas } \\
\text { internas de treinamento mais altas. } \\
\text { A percepção subjetiva de esforço afeta a } \\
\text { tolerância ao estresse. }\end{array}$ & $\begin{array}{c}\text { Dalda } \\
\text { Percepção } \\
\text { subjetiva de } \\
\text { esforço (PSE) }\end{array}$ \\
\hline $\begin{array}{l}\text { Estresse psicológico de } \\
\text { velejadores de alto nível } \\
\text { esportivo em competição } \\
\text { (SEGATO et al., 2010) }\end{array}$ & $\begin{array}{l}\text { Relatam baixos a moderados níveis de } \\
\text { estresse percebido, relacionados a fatores } \\
\text { intrínsecos e extrínsecos à competição. } \\
\text { Diferença estatisticamente relevante entre } \\
\text { níveis de estresse antes e depois das regatas, } \\
\text { sendo os níveis pré-competição maiores. } \\
\text { Relação inversamente proporcional entre } \\
\text { experiência na modalidade e nível de estresse } \\
\text { percebido. }\end{array}$ & $\begin{array}{l}\text { Escala de } \\
\text { Estresse } \\
\text { Percebido }\end{array}$ \\
\hline
\end{tabular}

Fonte: Elaborado pelos autores.

Para complementar as pesquisas empíricas, analisaram-se cinco revisões de literatura. Brandt et al. (2011) destacam a importância da correlação entre estados de humor e desempenho esportivo, na qual atletas em situação de elevado nível de vigor (fator positivo) associado a baixos níveis de fadiga, tensão, depressão e raiva (fatores negativos), geralmente apresentam melhor rendimento e desempenho esportivo. Alterações de humor também foram correlacionadas com lesões severas. Logo, uma carga elevada de humor negativo pode estar relacionada com lesão física (LEITE et al., 2011).

Outros pontos frequentemente discutidos nos artigos, tanto empíricos quanto de revisão, referem-se à importância da percepção individual do atleta sobre o seu desempenho e posicionamento no campeonato e aos recursos que ele tem para enfrentar as possíveis situações de estresse e ansiedade (SILVA; ENUMO, 2016b; LEITE et al., 2011; SILVA, 2012). A autoconfiança, portanto, é um elemento muito importante na performance esportiva. Alguns estudos mostram que quanto maiores forem os índices de autoconfiança, maior será a probabilidade de o atleta encarar uma competição como algo desafiador e não uma ameaça, o que impulsiona seu desempenho (LEITE et al., 2011). Isso significa que a autoconfiança ajuda o atleta a ter uma percepção positiva das situações competitivas, de modo a impulsionar seu desempenho. 
Silva e Enumo (2016b) também referem correlação inversamente proporcional entre o desempenho esportivo e os sintomas de estresse e ansiedade, possivelmente porque, uma vez que o atleta apresenta bom desempenho e bons resultados, há menos cobrança de terceiros.

Sobre bailarinos, há estudos que relatam que, para atingir o nível ótimo de ansiedade, devem-se trabalhar autoconfiança, motivação, respiração e recuperação. Dessa forma, o bailarino atingirá o máximo de suas potencialidades (SILVA, 2012). Outros trabalhos encontraram níveis de ansiedade aumentados em momentos anteriores às apresentações, principalmente na estreia de um espetáculo. Além disso, há uma diferença entre os sexos com relação à ansiedade: a mulher, ao que tudo indica, é mais propensa a ter níveis mais elevados. De acordo com Viscott (1982), a intensidade da reação emocional do indivíduo dependerá da severidade e importância da "ameaça".

Por fim, Silva et al. (2014) realizaram uma revisão que apresenta e discute os instrumentos aplicados em estudos brasileiros sobre psicologia do esporte. Os autores identificaram diferentes formas de avaliação que são utilizadas na área, como entrevistas, observações comportamentais, relatórios de treinadores, gravações em vídeos, testes, entre outros (MCCANN; JOWDY; VAN RAALTE, 2011). Com relação ao uso de testes, devem-se considerar as diferentes modalidades esportivas e suas demandas específicas, ou seja, se são esportes coletivos ou individuais e quais são as habilidades físicas, psicológicas e cognitivas exigidas para um bom desempenho. Todas essas variáveis, somadas às características individuais quanto a padrões comportamentais, devem ser levadas em consideração nos momentos de escolha do instrumento, coleta de dados e análise dos resultados (MCCANN; JOWDY; VAN RAALTE, 2011).

\section{Intervenção}

Por causa do número escasso de produções empíricas realizadas, a maioria dos artigos mencionados nessa categoria de análise refere-se a artigos de revisão que apontam alguns conceitos, modelos teóricos já desenvolvidos e resultados de estudos realizados no exterior sobre intervenções psicológicas para o controle e a diminuição de quadros de estresse e ansiedade ou para o desenvolvimento de estratégias de enfrentamento e compensação no âmbito do esporte.

Entretanto, foram encontradas algumas produções empíricas realizadas nos últimos sete anos, no Brasil. Em estudo com velejadores (SEGATO et al., 
2010), realizaram-se entrevistas abertas para a identificação de estratégias de enfrentamento do estresse. Esses resultados foram separados entre estratégias para situações do cotidiano e de competição. Em cada uma dessas categorias, as estratégias ainda foram organizadas em cognitivas (atuar nos modificadores de comportamento: pensamento, linguagem, percepção etc.) e somáticas (manifestações fisiológicas). Com relação à situação de competição, as estratégias somáticas de escutar música e dormir/descansar foram mais frequentemente apresentadas (22,6\%), seguidas pela estratégia cognitiva de isolar-se (13\%). As primeiras estão mais associadas às técnicas de relaxamento, enquanto a segunda está mais associada à fuga/esquiva do problema (SEGATO et al., 2010).

Akamine et al. (2016), em estudo sobre lesões em atletas de modalidades coletivas, buscaram identificar os aspectos psicológicos envolvidos com a utilização da escala RESTQ-Sport. Em uma escala de zero a seis do nível geral de eventos estressantes e tranquilizantes, as categorias mais pontuadas foram: autorregulação $(4,39)$; recuperação social $(4,23)$; bem-estar geral $(4,20)$; e aceitação pessoal $(4,14)$. Esses resultados apontam para a importância da autoconfiança, da autoeficácia e do apoio social como estratégias de prevenção e enfrentamento, lembrando a necessidade de adequar as estratégias para cada atleta e perfil de adversário (ZANETTI; MACHADO, 2010). O artigo ainda ressalta a importância de intervenções psicológicas, como técnicas de relaxamento, treinamento de confiança e ensaio positivo para controle de respostas de estresse (AKAMINE et al., 2016).

Ribeiro, Oliveira e Silva (2013) relatam, em revisão sobre intervenções psicológicas em atletas lesionados, um estudo realizado com remadores de uma equipe júnior de uma universidade norte-americana (PERNA et al., 2003), em que foi realizada uma intervenção de psicólogos no período pré-temporada. Nessa intervenção, foram ensinadas técnicas de relaxamento muscular progressivo, respiração diafragmática, visualização motora da ação, reestruturação cognitiva, entre outras. Como resultado, observou-se redução no número de lesões e de atendimentos em serviços de saúde (PERNA et al., 2003).

Ainda sobre atletas lesionados e o processo de reabilitação, Nunes et al. (2010) sintetizam alguns estudos científicos que descrevem intervenções no sentido de facilitar a prevenção e recuperação de futuras lesões. Quanto à prevenção, habilidades como resolução de problemas, tomada de decisão, autocontrole, relaxamento, formação de vínculos sociais e visualização mental serão essenciais para que o atleta esteja psicologicamente preparado para 
competições esportivas (NUNES et al., 2010). Em relação ao processo de reabilitação de atletas lesionados, há um conjunto de procedimentos propostos por Smith, Scott e Wiese (1990) para minimizar os custos e o tempo de tratamento. Tais procedimentos são divididos em quatro categorias: relaxamento, visualização mental, reestruturação cognitiva e diálogo interno.

Em outra revisão sobre ansiedade em bailarinos (SILVA, 2012), foram encontrados alguns resultados de intervenções que se mostraram eficazes no controle de sintomas, como: realização de feedbacks por parte do treinador, que colaboram no vínculo e aumentam o grau de motivação e autoconfiança do atleta; controle da respiração, que promove equilíbrio mental e relaxamento muscular; e técnicas de relaxamento, que induzem estados de sono para uma melhor qualidade de sono na véspera de apresentações.

Em revisão sobre esporte, estresse e burnout (VERARDI et al., 2012), as estratégias de enfrentamento foram definidas como respostas individuais de adaptação às situações difíceis. Frequentemente essas estratégias requerem o desenvolvimento de um novo repertório comportamental, sendo classificadas como focalizadas na emoção ou no problema (STRAUB, 2005). Estratégias com o foco na emoção são adotadas quando não há perspectiva de alteração da situação problema; nesses casos, opta-se pela fuga/esquiva ou reavaliação positiva da situação (STRAUB, 2005). Estratégias focadas no problema caracterizam-se por um contato direto com o estressor na intenção de minimizar a demanda ou aumentar a capacidade individual de lidar com esse estímulo (STRAUB, 2005).

Ruiz e Mojena (2002) desenvolveram um trabalho que sistematiza alguns princípios básicos para programas de intervenção e prevenção em atletas com síndrome de burnout. Destacam a necessidade de um sistema de avaliação para diagnóstico da síndrome e sua intensidade, sugerindo a utilização do instrumento MBI. Depois o psicólogo deve detectar as áreas que necessitam de intervenção, que podem ser: pessoais, esportivas ou familiares-sociais. Quanto à prevenção, os autores enfatizam a necessidade de um sistema de avaliação contínua, uma estruturação racional dos treinamentos físicos, o estabelecimento de programas de treinamento psicológico, a manutenção da motivação dos atletas, impedir que se inicie a espiral de saturação que culmina no abandono da prática esportiva e incentivar modificações na estrutura social do esporte competitivo, muitas vezes excessivamente controladora e autoritária (RUIZ; MOJENA, 2002). 


\section{Algumas intervenções psicológicas eficazes}

Vorraber (2010) analisa os processos cognitivos inerentes à prática esportiva e apresenta o conceito de reestruturação cognitiva como uma forma de promover desenvolvimento cognitivo nos atletas. Reestruturação cognitiva é o objetivo da terapia cognitiva, que busca reformular pensamentos distorcidos e desenvolver pensamentos mais adaptativos, de forma a modificar respostas emocionais disfuncionais. A autora ainda argumenta que esse tipo de intervenção seria o melhor instrumento no âmbito do esporte, pois se trata de uma intervenção dinâmica, breve, voltada ao presente e orientada por metas claramente estabelecidas (VORRABER, 2010).

Nessa mesma perspectiva, há a terapia de aceitação e compromisso (acceptance and commitment therapy - ACT). Tal intervenção busca promover a consciência e aceitação de eventos públicos e privados (encobertos) que podem ser positivos ou negativos. A partir dessa consciência, o indivíduo é capaz de realizar escolhas, a fim de não repetir erros, e de se colocar em ação, baseando-se nos seus valores e escolhas (SABAN, 2015).

Transpondo para o âmbito esportivo, seria trabalhar com os atletas a consciência e aceitação de reações emocionais inerentes à competição e suas respostas comportamentais ante as situações tanto no esporte como na vida pessoal, com o objetivo de torná-los capazes de responder de forma adequada sob controle de reforçadores positivos, mesmo com a presença simultânea de estimulação aversiva encoberta, como sintomas de ansiedade/estresse e pensamentos negativos. Isso significa desenvolver habilidades psicológicas e cognitivas para lidar com essas situações e agir de forma mais íntegra e consciente, com base em seus valores e escolhas.

Vorkapic e Rangé (2014) realizaram um dossiê que apresenta quais são as habilidades psicológicas necessárias para um atleta, dissertando sobre as práticas contemplativas e suas técnicas que podem auxiliar no desempenho esportivo. Essas intervenções já são largamente utilizadas no exterior; já no Brasil, possuímos alguns exemplos de times que vêm recebendo esse tipo de orientação, como lutadores profissionais de jiu-jítsu, que, após intervenção por técnicas de ioga, apresentaram níveis reduzidos de ansiedade, fadiga, tensão e raiva. Outra técnica apresentada é o mindfulness, uma atenção focada no momento presente sem qualquer tipo de julgamento ou crítica, a fim de desenvolver a consciência pessoal e assim diminuir o gasto de energia mental para a realização de tarefas (VORKAPIC; RANGÉ, 2014). Intervenções baseadas em mindfulness têm mostrado melhora na frequência de quadros de ansiedade e 
esquiva de estímulos pré-aversivos, além de promoverem maior aceitação da realidade e redução nos níveis de burnout (PALMI; SOLÉ, 2016).

\section{CONSIDERAÇÕES FINAIS}

Os objetivos do presente trabalho foram atingidos, uma vez que foi possível fazer a contabilização, organização e análise dos artigos de periódicos nacionais publicados dentro do período escolhido pelos pesquisadores. A partir da análise, foi possível perceber a utilização de vários instrumentos para a identificação de estados de estresse/ansiedade, bem como a apresentação de intervenções comportamentais para o seu enfrentamento.

Houve, naturalmente, limitações metodológicas neste trabalho. Os autores reconhecem que uma revisão mais ampla e criteriosa seja ainda necessária para melhor elucidação do tema. Reconhece-se a ainda crescente coleção de evidências da Psicologia Esportiva em âmbito nacional, sobretudo no tocante à coleta de dados com instrumentos validados para a população brasileira.

Quando aplicada a não atletas, a prática esportiva parece desenvolver maior capacidade de resiliência e índices mais altos de qualidade de vida, se realizada de forma adequada, ou seja, sem exceder as capacidades físicas, psíquicas e emocionais do indivíduo (CEVADA et al., 2012). Estudos apontam para a teoria de que todos os estímulos ambientais inerentes à prática esportiva, inclusive os desencadeadores de ansiedade/estresse, se bem trabalhados e resolvidos, auxiliam no desenvolvimento de habilidades cognitivas, resiliência, habilidades sociais, entre outras (FONTES; BRANDÃO, 2013). Portanto, a prática de esporte pode ser um meio de desenvolver habilidades e capacidades que serão importantes para toda a vida.

Conclui-se que o atleta, como sujeito biopsicossocial, deve ser analisado nessas três instâncias, e, no momento da avaliação e intervenção psicológica, devem-se considerar não apenas fatores do âmbito esportivo, mas também questões pessoais e fatores encobertos (estímulos privados).

Dessa forma, em uma etapa de avaliação, é necessário identificar os possíveis fatores estressantes para o atleta, as estratégias de enfrentamento de que ele dispõe e o nível de efetividade dessas estratégias. Esse conhecimento permite o delineamento de programas de prevenção e intervenção para situações adversas (VERARDI et al., 2012).

Aspectos como a autoconfiança e a autoavaliação positiva parecem ser fatores mais relevantes para um bom desempenho e níveis mais baixos de estresse e ansiedade do que fatores como idade, nível maturacional e tempo 
de experiência (SANTOS et al., 2012; PIZZI, 2015). A autoconfiança faz com que os atletas não percebam as situações como ameaçadoras e perigosas, ao contrário, eles as avaliam como desafiadoras e motivadoras. Esportistas com maior nível de autoconfiança também parecem dispor de mais recursos de enfrentamento, também chamadas de técnicas de coping, sejam elas com foco no problema (utilizando técnicas de relaxamento, apoio social, mentalização positiva, entre outras) ou estratégias de fuga/esquiva da situação, quando não há perspectiva de mudança do ambiente.

Algumas abordagens e técnicas de psicologia comportamental/cognitiva para promover o bem-estar e desenvolver habilidades psicológicas e cognitivas em atletas para que tenham o melhor desempenho são a reestruturação cognitiva, a ACT e a prática de meditação, como ioga e mindfulness.

Há muitas variáveis que interferem diretamente no desempenho esportivo e, se mal equacionadas, levam ao abandono da prática, ao esgotamento físico e psíquico (síndrome de burnout), às lesões, ao desgaste emocional e à emissão de respostas de ansiedade e estresse. Portanto, no momento da avaliação e intervenção psicológica, devem-se considerar os fatores do âmbito esportivo, a modalidade praticada, além de questões pessoais, possíveis fatores encobertos e técnicas de enfrentamento já aprendidas.

Observa-se que, quando o esporte competitivo é aliado ao bem-estar do atleta, este apresentará melhor desempenho. A atuação do psicólogo, nesse contexto, tem como objetivo principal o desenvolvimento de autoconsciência, autoconfiança, autoavaliação positiva, inteligência emocional e flexibilidade mental. Devemos considerar que é trabalho do psicólogo e responsabilidade da equipe técnica, em geral, promover o bem-estar dos atletas. Esse elemento, somado ao desenvolvimento de habilidades psicológicas e cognitivas, garante a melhor performance.

Sugere-se, portanto, que o trabalho do psicólogo do esporte seja, em conjunto com o atleta e toda a equipe técnica, garantir o bem-estar aliado ao alto padrão de desempenho do atleta. Para tanto, é imprescindível encorajar o desenvolvimento da inteligência emocional, a fim de promover consciência pessoal (de eventos públicos e privados), o controle das reações emocionais, por meio de técnicas provenientes de diversas ciências (ioga, meditação, mindfulness, entre outras), e a flexibilidade mental, de modo a permitir a reestruturação cognitiva, a adaptação às mudanças e a aceitação das situações adversas da vida, mantendo o foco em ações mais conscientes e alinhadas a valores e escolhas pessoais. 


\title{
An outlook of behavioral interventions to treat stress and anxiety in athletes: literature review
}

\begin{abstract}
Sports in contemporaneity have been gaining more and more importance and visibility, mainly for valuing the physical and intellectual effort made by high-performance athletes in its various categories. These athletes often face stress and anxiety before performing their duties. The objective of this study was to describe the factors that elicit these emotional reactions, present instruments used for the evaluation and diagnosis of these reactions in athletes, and present psychological and/or behavioral interventions that were used. A review of scientific articles published in Brazilian journals was carried out, including empirical and review studies published from year 2010 up to year 2017 on stress and anxiety situations in athletes. The theoretical reference used for the discussion of the subject was the analysis behavior and radical behaviorism. As a result, all background, evaluation tools and interventions were analyzed. Finally, some interventions presented in the literature are described as effective, but without empirical data collected so far in Brazil. It is concluded that when the competitive sport is allied to the well-being of athletes, they will present better performance. The role of the psychologist, in this context, should pursuit the development of self-consciousness, self-confidence and emotional intelligence.
\end{abstract}

\section{Keywords}

Sport psychology. Behavior. Stress. Anxiety. Performance.

\section{Un panorama de las intervenciones de comportamiento para tratar el estrés y la ansiedad en los atletas: revisión bibliográfica}

\section{Resumen}

El deporte, en la contemporaneidad, viene ganando cada vez más importancia y visibilidad, sobre todo por valorar el esfuerzo físico e intelectual desprendido por atletas de alto rendimiento en sus diversas categorías. Estos atletas a menudo se enfrentan a estrés y ansiedad antes de desempeñar sus funciones. Se objetivó con el presente trabajo describir los factores que elician estas reacciones emocionales, presentar instrumentos utilizados para la evaluación y diagnóstico de las mismas en atletas, y presentar intervenciones psicológicas y/o comportamentales que se utilizaron. Para ello, 
se procedió a una revisión bibliográfica de los artículos científicos publicados en periódicos nacionales, siendo incluidas investigaciones empíricas y de revisión, publicados entre el año 2010 y el año 2017 sobre situaciones de estrés y ansiedad en atletas. El referencial teórico utilizado para la discusión del tema fue el análisis del comportamiento y el behaviorismo radical. Como resultado se analizaron todos los antecedentes, instrumentos de evaluación e intervenciones realizadas. Al final se describen algunas intervenciones presentadas en la literatura como eficaces, pero sin datos empíricos recogidos hasta el momento en Brasil. Se concluye que, cuando el deporte competitivo es aliado al bienestar del atleta, éste presentará mejor desempeño. La actuación del psicólogo, en este contexto, tiene como objetivo principal el desarrollo de autoconciencia, autoconfianza e inteligencia emocional.

\section{Palavras clave}

Psicología del deporte. Comportamiento. Estrés. Ansiedad; Rendimiento.

\section{REFERÊNCIAS}

AKAMINE, M. V. S. et al. Estresse e lesões em atletas de esportes coletivos. Arquivos de Ciências da Saúde da Unipar, Umuarama, v. 20, n. 1, p. 25-31, jan./abr. 2016.

ALEXANDRE, B. Ansiedade pré-competitiva em modalidades de esporte coletivo e individual. 2010. 56 f. Trabalho de Conclusão de Curso (Graduação em Psicologia) - Universidade do Extremo Sul Catarinense, Criciúma, 2010.

ANTONIAZZI, A. S.; DELLAGLIO, D. D.; BANDEIRA, D. R. O conceito de coping: uma revisão teórica. Estudos de Psicologia, v. 3, n. 2, p. 273-294, jul./dez. 1998.

ANTUALPA, Kizzy Fernandes et al. Carga interna de treinamento e respostas comportamentais em jovens ginastas. Revista da Educação Física/UEM, Maringá, v. 26, n. 4, p. 583-592, dez. 2015.

BALBIM, G. M.; NASCIMENTO JUNIOR, J. R. A.; VIEIRA, L. F. Análise do nível de coesão de grupo e do estresse psicológico pré-competitivo de atletas adultos de voleibol. Revista Brasileira de Cineatropometria e Desempenho Humano, Londrina, v. 14, n. 6, p. 704-712, mar./jun. 2012.

BARBANTI, V. O que é esporte? Revista Brasileira de Atividade Física e Saúde, v. 11, n. 1, p. 54-58, abr. 2006.

BARBOSA, C.; SEABRA, A. G.; CALGARO, D. Validade de testes de atenção e ansiedade na predição do desempenho no handebol. Revista Thêma et Scientia, v. 1, n. 2, p. 130-141, jul./dez. 2011. 
BECKER JUNIOR, B. Manual de psicologia do esporte e exercício. Porto Alegre: Novaprova, 2000.

BERTUOL, L.; VALENTINI, N. C. Ansiedade competitiva de adolescentes: gênero, maturação, nível de experiência e modalidades esportivas. Revista da Educação Física/ UEM, Maringá, v. 17, n. 1, p. 65-74, 2006.

BIAGGIO, A. M. B.; NATALÍCIO, L.; SPIELBERGER, C. D. Desenvolvimento da forma experimental em português do Inventário de Ansiedade Traço-Estado (IDATE). Arquivos Brasileiros de Psicologia Aplicada, Rio de Janeiro, v. 29, n. 3, p. 31-44, jul./set. 1977.

BORGES, N. B.; CASSAS, F. A. Clínica analítico-comportamental: aspectos teóricos e práticos. Porto Alegre: Artmed, 2011.

BRANDT, R. et al. Relações entre os estados de humor e o desempenho esportivo de velejadores de alto nível. Psicologia: Teoria e Prática, Florianópolis, v. 13, n. 1, p. 117-130, mar. 2011.

BRITES, J. S. Análise do desempenho da seleção alemã de futebol na Copa do Mundo FIFA 2014, referente aos fundamentos: desarme, posse de bola, passes completados e chutes ao gol, durante os 15 minutos finais de cada partida e durante o tempo total de cada partida. Revista Brasileira de Futsal e Futebol, São Paulo, v. 7, n. 25, p. 332-337, maio/jun./jul./ago. 2015.

CAPUTO, E. L.; ROMBALDI, A. J.; SILVA, M. C. D. Sintomas de estresse pré- competitivo em atletas adolescentes de handebol. Revista Brasileira de Ciências do Esporte, Pelotas, v. 39, n. 1, p. 68-72, jan. 2014.

CEVADA, T. et al. Relação entre esporte, resiliência, qualidade de vida e ansiedade. Revista de Psiquiatria Clínica, Rio de Janeiro, v. 39, n. 3, p. 85-89, fev. 2012.

CILLO, E. N. P. Análise do comportamento e esporte. ABPMC, 2012. Disponível em: http://abpmc.org.br/arquivos/publicacoes/140536866221af9267.pdf. Acesso em: 10 ago. 2019.

CONSTANTINO, A. C.; PRADO, W. L.; PRADO, M. C. L. Ansiedade em bailarinos profissionais nas apresentações de dança. Revista da Faculdade de Educação Física da Unicamp, Campinas, v. 8, n. 3, p. 146-155, set./dez. 2010.

COUTO, H. A. Stress e qualidade de vida dos executivos. Rio de Janeiro: COP, 1987.

COZZANI, M.; MACHADO, A. A.; VIEIRA, E. C.; NASCIMENTO, A. L. Ansiedade: interferências no contexto esportivo. In: MACHADO, A. A. (org.) Psicologia do esporte: temas emergentes. Jundiaí: Fontoura, 1997. p. 109-121.

FERREIRA, S. et al. Reeducation of pelvic floor muscles in volleyball athletes. Revista da Associação Médica Brasileira, São Paulo, v. 60, n. 5, p. 428-433, out. 2014.

FIELDING, N. Ethnography. In: GILBERT, N. (org.) Researching social life. London: Sage, 1993. 
FONTES, R. C. C.; BRANDÃO, M. R. F. A resiliência no âmbito esportivo: uma perspectiva bioecológica do desenvolvimento humano. Motriz, Rio Claro, v. 19, n. 1, p. 151-159, jan./mar. 2013.

FREITAS, C. G. et al. Carga interna, tolerância ao estresse e infecções do trato respiratório superior em atletas de basquetebol. Revista Brasileira de Cineantropometria e Desempenho Humano, v. 15, n. 1, p. 49-59, jan./fev. 2013.

FREITAS, V. H. et al. Efeito de quatro dias consecutivos de jogos sobre a potência muscular, estresse e recuperação percebida, em jogadores de futsal. Revista Brasileira de Educação Física e Esporte, São Paulo, v. 28, n. 1, p. 23-30, jan./mar. 2014.

GONÇALVES, M. P.; BELO, R. P. Ansiedade-traço competitiva: diferenças quanto ao gênero, faixa etária, experiência em competições e modalidade esportiva em jovens atletas. Psico, São Paulo, v. 12, n. 2, p. 301-307, jul./dez. 2007.

GRÜNSPUN, H. Distúrbios neuróticos da criança. 2. ed. Rio de Janeiro: Ateneu, 1966.

INTERDONATO, G. C. et al. Análise da ansiedade traço competitiva em jovens atletas. Revista da Faculdade de Educação Física da Unicamp, Campinas, v. 8, n. 3, p. 1-9, set./dez. 2010.

LAZARUS, R. S.; FOLKMAN, S. Stress, appraisal, and coping. New York: Springer, 1984.

LEITE, C. D. et al. Representações de ansiedade e medo de atletas universitários. Revista Brasileira de Psicologia do Esporte, São Paulo, v. 6, n. 1, p. 36-46, jan./jun. 2016.

LEITE, G. S. F. et al. Influência do estresse em eventos competitivos relacionados à dança. Revista Digital, Buenos Aires, ano 15, n. 153, fev. 2011.

LIPP, M. E. N. O stress está dentro de você. São Paulo: Contexto, 2000.

MACHADO, A. A. (org.). Psicologia do esporte: temas emergentes. Jundiaí: Fontoura, 1997.

MACHADO, T. D. A. et al. Ansiedade estado pré-competitiva em atletas de voleibol infanto-juvenis. Revista Brasileira Educação Esporte, São Paulo, v. 30, n. 4, p. 1061-1067, out./dez. 2016.

MATOS, F. D. O. et al. Cargas elevadas de treinamento alteram funções cognitivas em jogadores de futebol. Revista Brasileira de Medicina do Esporte, v. 20, n. 5, p. 388-393, set./out. 2014.

MOLINA, O. Estresse no cotidiano. São Paulo: Pancast, 1996.

MOREIRA, A. et al. Percepção de esforço da sessão e a tolerância ao estresse em jovens atletas de voleibol e basquetebol. Revista Brasileira de Cineantropometria e Desempenho Humano, v. 12, n. 5, p. 345-351, 2010.

NEVILL, A. M.; HOLDER, R. L. Home advantage in sport: an overview of studies on the advantage of playing at home. Sports Medicine, Auckland, v. 28, n. 4, p. 221-236, 1999. 
NOCE, F. et al. Análise dos sintomas de overtraining durante os períodos de treinamento e recuperação: estudo de caso de uma equipe feminina da superliga de voleibol 2003/2004. Revista Brasileira de Medicina do Esporte, v. 17, n. 6, p. 397-400, nov./dez. 2011.

NOGUEIRA, F. C. D. A. et al. Influência das cargas de treinamento sobre o rendimento e os níveis de recuperação em nadadores. Revista Educação Física, Maringá, v. 26, n. 2, p. 267-278, 2015.

NUNES, C. R. D. O. et al. Processos e intervenções psicológicas em atletas lesionados e em reabilitação. Revista Brasileira de Psicologia do Esporte, São Paulo, v. 3, n. 4, p. 130-146, jan./jun. 2010.

PALMI, J.; SOLÉ, S. Intervenciones basadas en mindfulness (atención plena) en psicología del deporte. Revista de Psicología del Deporte, Barcelona, v. 25, n. 1, p. 147-155, 2016.

PAYNE, W. L. A study of emotion: developing emotional intelligence; self-integration; relating to fear, pain and desire. 1986. $934 \mathrm{f}$. Dissertation (Doctor of Philosophy ) - The Union for Experimenting Colleges and Universities, Ann Arbor, 1986.

PERNA, F. et al. Cognitive behavioral stress management effects on injury and illness among competitive athletes: a randomized clinical trial. Annual of Behavioral Medicine, v. 25, n. 1, p. 66-73, 2003.

PIRES, D. A.; BRANDÃO, M. R. F; MACHADO, A. A. A síndrome de burnout no esporte. Motriz, Rio Claro, v. 11, n. 3, p. 147-153, set./dez. 2005.

PIZZI, M. V. G. Estresse psicológico e desempenho de atletas juniores: uma análise documental. 2015. 43 f. Trabalho de Conclusão de Curso (Graduação em Educação Física) - Universidade Estadual Paulista "Júlio de Mesquita Filho", Rio Claro, 2015.

PIZZI, S.; BARRETA, E.; GRIGOLLO, L. R. A ansiedade como fator preponderante no desempenho de jovens atletas: incidência dos sintomas estressores no período précompetitivo em escolares do ensino fundamental anos finais inseridos em ações do PIBID. Anuário Pesquisa e Extensão Unoesc Joaçaba, Joaçaba, SC, v. 1, p. e12474, nov. 2016.

RIBEIRO, V. B.; OLIVEIRA, S. R. G.; SILVA, F. G. Preditores psicológicos, reações e o processo de intervenção psicológica em atletas lesionados. Ciência \& Cognição, São Paulo, v. 18, n. 1, p. 70-88, 2013.

ROSE JUNIOR, D. A competição como fonte de estresse no esporte. Revista Brasileira de Ciência e Movimento, Brasília, v. 10, n. 4, p. 19-26, out. 2002.

RUIZ, E. J. G. de los F; MOJENA, G. M. Princípios básicos a aplicar en el desarrollo de programas de intervención y prevención en deportistas con el síndrome de burnout. Propuesta desde una perspectiva transnacional. Revísta de Psicología del Deporte, v. 11, n. 2, p. 259-267, 2002. 
SABAN, M. T. Introdução à terapia de aceitação e compromisso. 2. ed. Belo Horizonte: Artesã, 2015. 104 p.

SANTOS, P. B. D. et al. Fatores geradores de estresse para atletas da categoria de base do futebol de campo. Motriz, Rio Claro, v. 18, n. 2, p. 208-217, abr./jun. 2012.

SANTOS, S. G.; PEREIRA, S. A. Perfil do nível de ansiedade-traço pré-competitiva de atletas de esportes coletivos e individuais do Estado do Paraná. Movimento, Porto Alegre, v. 4, n. 6, p. 3-13, 1997.

SEGATO, L. et al. Estresse psicológico de velejadores de alto nível esportivo em competição. Motricidade, v. 6, n. 3, p. 53-62, 2010.

SILVA, A. M. B. D. et al. Instrumentos aplicados em estudos brasileiros em psicologia do esporte. Estudos Interdisciplinares em Psicologia, Londrina, v. 5, n. 2, p. 77-95, dez. 2014.

SILVA, A. M. B.; ENUMO, S. R. F. Dor e lesões em bailarinos adolescentes: revisão sistemática. Revista Dor, São Paulo, v. 17, n. 2, p. 132-135, jun. 2016a.

SILVA, A. M. B.; ENUMO, S. R. F. Estresse em atletas de modalidades coletivas: uma revisão sistemática. Arquivos em Movimento, Campinas, v. 12, n. 1, p. 91-105, jan./jun. 2016b.

SILVA, C. A. A ansiedade em bailarinos. 2012. 35 f. Trabalho de Conclusão de Curso (Graduação em Educação Física) - Universidade Estadual Paulista "Júlio de Mesquita Filho", Rio Claro, 2012.

SILVA, M. M. F. D. et al. Ansiedade e desempenho de jogadores de voleibol em partidas realizadas dentro e fora de casa. Revista Educação Física/UEM, Maringá, v. 25, n. 4, p. 585-596, 2014.

SKINNER, B. F. Science and human behavior. New York: Simon \& Schuster, 1965.

SMITH, A. M.; SCOTT, S. G.; WIESE, D. M. The psychological effects of sports injuries coping. Sports Medicine, v. 9, n. 6, p. 352-369, 1990.

SONOO, C. N. et al. Ansiedade e desempenho: um estudo com uma equipe infantil de voleibol feminino. Motriz, Rio Claro, v. 16, n. 3, p. 629-637, jul./set. 2010.

SONSTROEM, R. J. Exercise and self-esteem. Exercise and Sport Sciences Reviews, v. 12, n. 1, p. 123-156, jan. 1984.

SOUZA, F. N. G.; MARIANI, M. E.; SAMULKI, D. M. Análise do nível de estresse e da ansiedade em bailarinos e bailarinas profissionais na pré-estreia de um espetáculo de dança. Revista da Faculdade de Educação Física da Unicamp, Campinas, v. 8, n. 3, p. 146-155, set./dez. 2010.

SOUZA, W. S.; COSTA, P. G. Análise do estresse psíquico em atletas de futebol sub-17 no período pré-competitivo. Revista Brasileira de Futebol, v. 8, n. 1, p. 62-75, jan./jul. 2017. 
SPIELBERGER, C. D. Anxiety: current trends in theory and research: I. Oxford, England: Academic Press, 1972.

SPIELBERGER, C. D. Understanding stress and anxiety. New York: Harper \& Row, 1979. STRAUB, R. O. Psicologia da saúde. Porto Alegre: Artmed, 2005.

VERARDI, C. E. L. et al. Esporte, stress e burnout. Estudos de Psicologia, Campinas, v. 29, n. 3, p. 305-313, set. 2012.

VIEIRA, L. F. et al. Autoeficácia e nível de ansiedade em atletas jovens do atletismo paranaense. Revista Brasileira de Cineantropometria e Desempenho Humano, Maringá, v. 13, n. 3, p. 183-188, ago./jan. 2011.

VISCOTT, D. S. A linguagem dos sentimentos. 13. ed. São Paulo: Summus, 1982. 135 p.

VORKAPIC, C. F.; RANGÉ, B. Reducing the symptomatology of panic disorder: the effects of a yoga program alone and in combination with cognitive-behavioral therapy. Frontiers in Psychiatry, v. 5, p. 1-7, dez. 2014.

VORRABER, G. A. Análise dos processos cognitivo-afetivos inerentes ao desempenho tático-esportivo. Revista Brasileira de Terapias Cognitivas, Rio de Janeiro, v. 6, n. 2, p. 144-166, dez. 2010.

WEINBERG, R. S.; GOULD, D. Fundamentos da psicologia do esporte e do exercício. 2. ed. Porto Alegre: Artmed, 2001.

ZANETTI, M. C.; MACHADO, A. A. Comportamento no nível de ansiedade de atletas de futsal nos jogos regionais de Atibaia - 2009. Coleção Pesquisa em Educação Fúsica, São Paulo, v. 9, n. 2, p. 85-90, 2010. 